BNL 51140

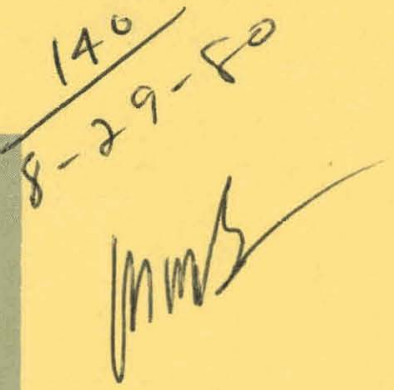

\title{
INTERGROUP WELFARE COMPARISONS \\ USING AGGREGATE CONSUMPTION DATA
}

\author{
Dale W. Jorgenson, Lawrence J. Lau, thomas M. Stoker
}

August 1979

NATIONAL CENTER FOR ANALYSIS OF ENERGY SYSTEMS DEPARTMENT OF ENERGY AND ENVIRONMENT

BROOKHAVEN NATIONAL LABORATORY UPTON, NEW YORK 11973 


\section{DISCLAIMER}

This report was prepared as an account of work sponsored by an agency of the United States Government. Neither the United States Government nor any agency Thereof, nor any of their employees, makes any warranty, express or implied, or assumes any legal liability or responsibility for the accuracy, completeness, or usefulness of any information, apparatus, product, or process disclosed, or represents that its use would not infringe privately owned rights. Reference herein to any specific commercial product, process, or service by trade name, trademark, manufacturer, or otherwise does not necessarily constitute or imply its endorsement, recommendation, or favoring by the United States Government or any agency thereof. The views and opinions of authors expressed herein do not necessarily state or reflect those of the United States Government or any agency thereof. 


\section{DISCLAIMER}

Portions of this document may be illegible in electronic image products. Images are produced from the best available original document. 
BNL 51140

UC-95C

(Energy Conservation-Modeling

and Performance Assessment - TID-4500)

\title{
INTERGROUP WELFARE COMPARISONS USING AGGREGATE CONSUMPTION DATA
}

\author{
DALE W. JORGENSON \\ Harvard University \\ LAWRENCE J. LAU \\ Stanford University \\ THOMAS M. STOKER \\ Massachusetts Institute of Technology \\ August 1979 \\ ECONOMIC ANALYSIS DIVISION \\ NATIONAL CENTER FOR ANALYSIS OF ENERGY SYSTEMS \\ DEPARTMENT OF ENERGY AND ENVIRONMENT \\ - BROOKHAVEN NATIONAL LABORATORY \\ ASSOCIATED UNIVERSITIES, INC.
}

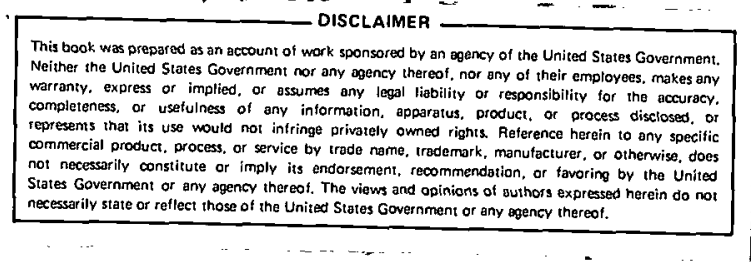

PREPARED FOR THE OFFICE OF POLICY, PLANNING AND EVALUATION, CONSERVATION AND SOLAR APPLICATIONS, U.S. DEPARTMENT OF ENERGY UNDER CONTRACT NO. DE-AC02-76CH00016 


\section{DISCL $\Lambda$ IMER}

This book was prepared as an account of work sponsored by an agency of the United States Covernment. Neither the United Stateo Covernment nor any agency thorcof, nor any of their employees, makes any warranty, express or implied, or assumes any legal liability or responsibility for the accuracy, completeness, or usefulness of any information, apparatus, product, or process disclosed, or represents that its use would not infringe privately owned rights. Reference herein to any specific commercial product, process, or service by trade name, trademark, manufacturer, or otherwise, does not necessarily constitute or imply its endorsement, recommendation, or favoring by the United States Government or any agency thereof. The views and opinions of authors cxpressed herein do not necessarily state or reflect those of the United States Government or any agency thereof.

Printed in the United States of America Available from

National Technical Information Service

U.S. Department of Commerce

5285 Port Royal Road

Springfield, VA 22161

Price: Printed Copy $\$ 4.50$; Microfiche $\$ 3.00$ 
$\Lambda$ BSTRACT

In this paper, the distributional impact of President Carter's domestic oil price decontrol program on different groups of households in the economy, distinguished by income, age of head of household, size of household, region (Northeast, North Central, South and West), residential location (urban-rural) and race (white-non-white), is explored. The specific question being addressed is: How much additional disposable income (called compensating variation, which may be negative) should be given to each group of household in order that its level of satisfaction remains the same as in the absence of the President's decontrol program? By comparing these "compensating variation" numbers across households, it is possible to infer the distribution of welfare gains and losses amongst households as a result of the decontrol program.

The analysis shows that on the whole; rural households are made much worse off than urban households (holding income and other attributes constant). The white households are made worse off than the non-white households (again, holding income and other attributes constant), but not by much. In terms of regional impact, the South is best off, followed by the West, followed by the Northeast. North Central requires the largest compensation. Low income households $(\$ 8,000)$ are hurt much more proportionately than high income households $(\$ 17,000)$.

The methodology employed is new. It consists of first identifying and constructing utility functions for different groups of households in the economy from aggregate consumption data, supplemented by data on the joint distribution of incomes and attributes. Given these group-specific utility tunctions, compensating variation calculations are done for each group of household corresponding to changes in policy. This methodology is perfectly general and can be applied to the synthetic fuels program or the conservation program or any combination of the two to determine the wel fare distribution consequences.

The distinguishing feature of this methodology is that it can be implemented using only aggregate time-series consumption data, supplemented by data on the joint distribution of incomes and attributes, and does not require time-series consumption data for individual groups which are typically unavailable. Moreover, the computations can be done quickly and inexpensively without costly and time-consuming microeconomic simulations. 
CONTENTS

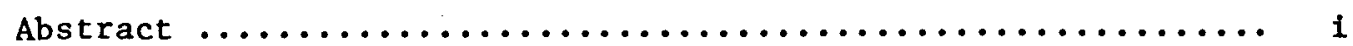

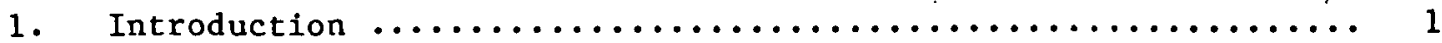

2. Determination of Group-Specific Ut1lity Functions. from Aggregate Consumption Data ............................. 4

3. Empirical Implementation $\ldots \ldots \ldots \ldots \ldots \ldots \ldots \ldots \ldots \ldots \ldots \ldots$,

4. Analysis of Compensating Variations $\ldots \ldots \ldots \ldots \ldots \ldots \ldots \ldots \ldots, 12$

5. Application for Long-Term Projection ................. 14

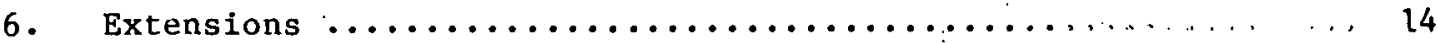

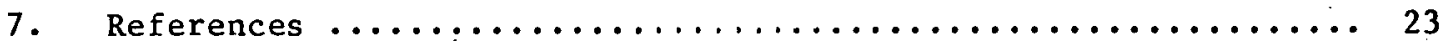

TARI.F.S

1. Scenario 175-2 Price Projections (Normalized to 1 in 1972) ... 16

2. Scenario 175-2 1979 Income $\$ 17,000$ Income and Expenditure

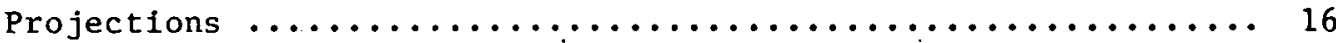

3. Scenario 175-2 1979 Income $\$ 17,000$ Compensated Varlations .... 17

4. Scenario 175-2 Income $\$ 17,000$ Minus vet Cimpensating

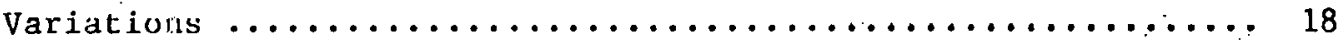

5. Scenario 175-2 1979 Income $\$ 17,000$ Typical Expenditure Patterns ....................................... 19

6. Scenario 175-2 1979 Income $\$ 8,000$ Income and Expenditure Projections ................................... 19

7. Scenario 175-2 1979 Income $\$ 8,000$ Compensation Variations .... 20

8. Scenario 175-2 1979 Income $\$ 8,000$ Minus Net Compensation Variations .................................. 21

9. Scenario 175-2 1979 Income $\$ 8,000$ Typical Expenditure

Patterns ...................................... 22 


\section{INTRODUCTION}

An important aspect of development policy or project evaluation is the determination of its differential impact on different groups of households in the economy. Which groups are likely to benefit the most? Which groups are likely to benefit the least? How do the distributions of welfare amongst different groups of households compare before and after the implementation of the policy or project? These are important questions that are continually faced by development planners and policymakers.

In order to evaluate the distribution of welfare amongst different groups of households in an economy, it is first of all necessary to know each group's utility function (up to a monotonic transformation). For the present discussion, it is useful to assume that all households belonging to the same group are identical. This assumption is made only for convenience and may be replaced by a much weaker assumption on the distribution of utility functions over the households belonging to the same group. Groups of households may be distinguished by observable attributes, which include the size and composition of the household (by age and sex); age, sex, and education of the head of household; ethnicity; religion; and other attributes that are relevant in the determination of demand patterns.

Given knowledge of each group's utility function (up to a monotonic transformation), it is possible to perform compensating variation calculations separately for each group of households. For example, let $\mathrm{V}(\mathrm{p} / \mathrm{M}, \mathrm{A})$ be the indirect utility function of a member of the group of households with a vector of attributes equal to $A$. . Let $P_{0}$ and $M_{0}$ be the base period (before the implementation of the policy or project) vectors. of prices and income respectively. Then the base period utility level of the household is given by $V\left(p_{0} / M_{0}, A\right)-v_{0}$. Corresponding to the indirect utility function $V(\cdot)$, there is an expenditure function $M$ ( $P$, $V$, A) which gives the minimum expenditure required for the household to achieve utility level $\mathrm{V}$ at prices $\mathrm{p}$. In the base period, assuming that the household maximizes utility,

$$
M\left(p_{0}, v_{0}, A\right)=M_{0} \text {. }
$$


Now suppose that as a result of the implementation of the policy or project, the price vector changes from $p_{0}$ to $p_{1}$ and the income for $a$ household with a vector of attributes equal to $A$ changes from $M_{0}$ to $M_{1}$, then in order for this household to maintain its utility at the same level $v_{0}$ as before, the minimum expenditure required is given by $M\left(p_{1}, v_{0}\right.$, A). Then the compensating variation for this household (relative to the base period) is given by

$$
C V=M\left(P_{1}, V_{O}, A\right)-M_{0} .
$$

However, since income of the household has also undergone a change in the process, one may define a concept of net compensating variation as

$$
\begin{aligned}
C V^{*} & =C V-\left(M_{1}-M_{0}\right) \\
& =M\left(p_{1}, v_{0}, A\right)-M_{0}-\left(M_{1}-M_{0}\right) \\
& =M\left(P_{1}, V_{0}, A\right)-M_{1} .
\end{aligned}
$$

The net compensating variation measures the additional expenditure (possibly negative for some groups) that is required to maintain a household with a vector of attributes equal to $A$ at its base period level of utility, taking into account both price and income changes.

It is clear that if the net compensating variation for a group is positive, then the group is worse off than before. If the net compensating variation is negative, then the group is better of $f$ than before. Since CV* depends on $A$ in addition to $P_{1}, M_{1}$, and $V_{n}$, it is group specific, reflecting the differential tastes and needs of each group. Thus, the group-specific compensating variations $c$ an be used collectively: to assess the distribution of welfare gains and losses across different groups resulting from the implementation of the policy or project. This exercise also identifies those groups of househulds which are most sig nificantly affected. In addition, it is a theorem in welfare economics that if the sum of the net compensating variations across all households is negative, then it is possible to find a redistribution scheme so that every household is either better off or, at least, as well off as during the base period, as a result of the implementation of the policy or project. 
One advantage of compensating variation calculations is that they are independent of the particular monotonic transformation chosen for the utility function of each group. Another advantage is that they do not require ethical judgments as to how the welfare of the different groups should be valued. The disadvantage of compensating variation calculations is that in general they do not lead to a transitive ranking of the desirability of policies or projects.

A natural alternative to compensating variation calculations is to postulate the existence of a social welfare function of the BergsonSamuelson type defined over the utilities of all the households in the economy:

$$
w=W\left[v_{1}\left(p, M_{1}, A_{1}\right), \ldots, v_{N}\left(p, M_{N}, A_{N}\right)\right]
$$

Social valuation of a policy or project then can be carried out by inserting the appropriate values for the vector of prices and the incomes of each household (or group of households).

The possibility of such a social valuation, given the form of the social welfare function, depends on having representations of the individual household utility functions which are in some sense comparable across households. Given these representations, there are various axioms that one can impose on the social welfare function so as to restrict its admissible functional form further. It is not our intention to discuss the axioms here. We merely observe that the determination of appropriate representations for the utility function of different groups so that they are socially comparable is logically prior to the application of the sorial wel fare axioms.

However, we also know that utility functions are in general determined only up to a monotonic transformation, which makes the problem of representation rather complicated. Fortunately it turns out that for the class of utility functions which allows identification from aggregate consumption data, there is a cardinal representation which is unique up to a positive linear transformation. There is of course still the positive scalar multiplier that needs to be determined. Nevertheless, having 
a cardinal representation is a necessary first step to the determination of relative social valuation between households with different vectors of attributes.

\section{DETERMINATION OF GROUP-SPECIFIC UTILITY FUNCTIONS FROM AGGREGATE CONSUMPTION DATA}

In order to derive empirically based group-specific utility functions, we need to know group-specific consumer demand functions. How ever, past efforts to estimate group-specific demand functions empirically have been stymied by (1) the absence of time-series data on consumption demands by consumer groups; (2) the absence of price variations on cross-section household consumption data; and (3) the restrictiveness of the assumptions necessary to derive the group-specific demand functions from time-series aggregate consumption data. We shall elaborate on each of these three points in turn.

First, if time-series data on the consumption of specific groups of households distinguished by their attributes are available, then it is straightforward to estimate, for each specific group, its own specific system of consuner demand functions. From these systems of consumer demand functions, one can construct, for each group, its own utility function (up to a monotonic transformation). Unfortunately, such time-series data are extremely difficult to come by.

Second, there is a relative abundance of cross-section household consumption data. The consumption data are usually accompanied by a wealth of information on household attributes. However, cross-section data usually suffer from a lack of price variation, which means that while the Engle curves of each group of households can be estimated with considerable precision, it is not in general possible to identify the effects of prices on demands, and hence not in general possible to construct the indirect utility function.

Third, if only time-series aggregate consumption data are available in addition to time-series prices and income data, then the traditional approach to the analysis of aggregate consumption data can be justified only under very strong assumptions on the form of the consumer demand 
functions. Specifically, the demand functions of all groups must be linear in income with a slope that is common to all groups.

This result was first derived by Gorman ${ }^{1}$. It can be simply demonstrated as follows. Suppose that the demand function for the $i^{\text {th }}$ household with income $M_{i}$ and vector of attributes $A_{i}$ is given by $f_{i}\left(p, M_{i}, A_{i}\right)$. But individual household demands are unobserved. What is observed is aggregate demand,

$$
\Sigma_{i} f_{i}\left(p, \Sigma_{i} M_{i}, \Sigma_{i} A_{i}\right),
$$

where $\Sigma_{i} M_{i}$ is aggregate income and $\Sigma_{i} A_{i}$ is a vector of aggregate attributes. (Since the total number of households $N$ is given, one may also assume $\Sigma_{i} A_{i}$ to be a vector proportional to the mean attributes.)

Now in order for the macro-demand function to be consistent with the micro-demand functions one must have for all $M_{i}{ }^{\prime} s$ and $A_{i}{ }^{\prime} s$,

$$
\Sigma_{i} f_{i}\left(p, M_{i}, A_{i}\right)=F\left(p, \Sigma_{i} M_{i}, \Sigma_{i} A_{i}\right) \text {. }
$$

Differentiating both sides with respect to $M_{j}$, we obtain

$$
\frac{\partial f_{j}}{\partial M_{j}}\left(p, M_{j}, A_{j}\right)=\frac{\partial F}{\partial \Sigma_{i} M_{i}}\left(p, \Sigma_{i} M_{i}, \Sigma_{i} A_{i}\right),
$$

which. leads to

$$
\begin{aligned}
& \frac{\partial f_{j}}{\partial M_{j}} \quad\left(p, M_{j}, A_{j}\right)=h_{1}(p), \forall_{j} \\
& \frac{\partial E}{\partial A_{j}} \quad\left(p, M_{j}, A_{j}\right)=h_{2}(p), \forall_{j}
\end{aligned}
$$

so that

$$
\begin{aligned}
& f_{j}\left(p, M_{j}, A_{j}\right)=h_{1}(p) M_{j}+h_{2}(p) A_{j}+k_{j}(p) \\
& F(\cdot)=h_{1}(p)\left(\Sigma_{j} M_{j}\right)+h_{2}(p)\left(\Sigma_{j} A_{j}\right)+\left[\sum_{j} k_{j}(p)\right] .
\end{aligned}
$$


Note that this implies that the Engel curves of all households are linear in income with the same identical slope. If, in addition, we Impose the restriction that aggregate demand is zero if aggregate income 18 zero, then $h_{2}(p)=0$ and $\left[\Sigma_{j} k_{j}(p)\right]=0$. Finally, by invoking nonnegativity of individual household demands, we have $k_{j}(p) \geqq 0, \forall_{j}$, which together with $\left[\Sigma_{j} k_{j}(p)\right]=0$ implies that $k_{j}(p)=0 ; v_{j}$.

Now with $h_{2}(p)=0$ and $k_{j}(p)=0$, each household demand function then becomes

$$
f_{j}\left(p, M_{j}, A_{j}\right)=h_{1}(p) M_{j} .
$$

It follows that one can indeed recover the Individual household demand functions from the aggregate demand function -- trivially, it turns out, since all individual household demand functions are identical.

The difficulty with the traditional approach lies not only in its intuitively unappealing theoretical implication that all households have identical demand and hence identical utility functions but also in its total refutation by every piece of empirical evidence from consumer research to date. Engel curves estimated from cross-section household data Indicate that they are neither identical (even up to an additive constant) across households with attributes nor linear in income. So that even in its weaker form (without imposing zero aggregate demand for zero aggregate income), the implication of linearity of the Engel curve in income cannot be supported empirically.

Thus, we have seen that the traditional approach to the analysis of aggregate consumption data has come to a. dead end. A new approach is needed. One new approach has been introduced in Lau. ${ }^{3,4}$ As before, let the individual household demand function be $f_{i}\left(p, M_{i}, A_{i}\right)$. However, the aggregate demand function is postulated to be a function:

$$
\begin{aligned}
& F\left[p, g_{1}\left(M_{1}, \ldots, M_{N} ; A_{1}, \ldots, A_{N}\right),\right. \\
& \left.\ldots, g_{S}\left(M_{1}, \ldots, M_{N} ; A_{1}, \ldots, A_{N}\right)\right],
\end{aligned}
$$

where the $g_{i}(\cdot)$ 's are symmetric with respect to the subscripts on $M$ and A. Examples of such symetric functions include

$$
g_{1}(\cdot)=\Sigma_{i} M_{i}
$$




$$
\begin{aligned}
& g_{2}(\cdot)=\Sigma_{1} A_{1} M_{1} \\
& g_{3}(\cdot)=\Sigma_{1} M_{i}^{2} \\
& g_{4}(\cdot)=\Sigma_{i} \Sigma_{j} M_{1} M_{j}
\end{aligned}
$$

Thus, this generalization includes the traditional $F\left(p, \Sigma_{1} M_{1}, \Sigma_{1} A_{1}\right)$ as a special case. To eliminate triviality it is furthermore assumed that the set of $g_{1}(\cdot)^{\prime} s, 1=1, \ldots, s$, form a set of independent functions. Note that the symmetry condition on the $g_{i}(\cdot)$ 's implies that the values of these functions may be determined from a knowledge of the joint distribution of $M$ and $A$ alone. It is not necessary to Identify each household individually. Thus, the $g_{1}(\cdot)$ 's can be estimated from a sample survey.

As- before, one can consider the implications of micro-macro consistency. It is shown in Lau. 3,4 that

$$
\Sigma_{i} f_{1}\left(p, M_{1}, A_{1}\right)=F\left[p, g_{1}\left(M_{1}, \ldots, M_{N} ; A_{1} ; \ldots, A_{N}\right), \ldots, g_{s}\left(M_{1}, \ldots, M_{N} ;\right.\right.
$$

implies

$$
f_{i}\left(p, M_{i}, A_{i}\right)=\sum_{j=1}^{s} h_{j}(p) g_{j}^{*}\left(M_{i}, A_{i}\right),
$$

and

$$
F(\cdot)=\Sigma_{j=1}^{S} h_{j}(p)\left[\Sigma_{i=1}^{N} g_{j}^{*}\left(M_{1}, A_{1}\right)\right] .
$$

If, in addition, it is assumed that the individual demand functions satisfy

(i) summability,

(ii) zero degree homogeneity,

then, for the case $s=2$,

$$
f_{1}\left(p, M_{1}, A_{1}\right)=\left\{\begin{array}{l}
h_{1}(p) M_{1}+h_{2}(p) \ell\left(\Lambda_{1}\right)\left(M_{1}\right)^{\sigma} \\
h_{1}(p) M_{1}+h_{2}(p) \cdot\left[\ell\left(A_{1}\right) M_{1}+M_{1} \ell M_{i}\right] .
\end{array}\right.
$$


Higher order cases are analogous.

Thus

$$
F(\cdot)=\left\{\begin{array}{l}
h_{1}(p)\left[\Sigma_{1} m_{1}\right]+h_{2}(p)\left[\Sigma_{i} \ell\left(A_{1}\right)\left(M_{i}\right) \sigma\right] \\
h_{1}(p)\left[\Sigma_{1} M_{1}\right]+h_{2}(p)\left[\Sigma_{i} \ell\left(A_{1}\right) M_{1}\right]+h_{2}(p)\left[\Sigma_{1} M_{i} \ell n M_{1}\right] \cdot
\end{array}\right.
$$

Note that very strong restrictions are imposed on the possible forms of Engel curves. The income term must enter either as a power function or a power function times a power of the natural logarithmic function.

But does there exist an Integrable system of rnnsumer demand functions which have these forms? The answer is affirmative. One example of such a system is that which corresponds to a special case of the translog indirect utility function, which will be discussed in the next section.

It is clear from the form of the aggregate demand function that one can derive from it the Individual household demand function corresponding to a particular set of attributes. Thus, there is a unique decompostion of the aggregate demand into group-specific household demands.

The distinguishing features of our new model of aggregate consumer demand are

(1) ability to accept directly full or partial information on the joint distribution of incomes and demographic characteristics;

(2) ability to identify uniquely the Individual household consumer demand functions which depend on prices as well as on income of individual consumer groups distinguished by demographic characteristics;

(3) ability to recover the utility function of individual consumer groups and hence to perform compensating variation calculations;

(4) full consistency between the mfcroeconomic model of individual consumer behavior and the macroeconomic model of aggregate consumer behavior; and

(5) ability to combine consistently. time-series aggregate consumption data and cross-sectional individual household consumption data.

To implement our new model of aggregate consumer demand, only the following data are noeded:

(1) aggregate time-series consumption expenditures data on specific commodities; 
(2) aggregate time-series data on priccs of consumption commodities;

(3) a time-series of income surveys (providing information on the joint distribution of income and attributes); and

(4) optional -- one or more cross sections of household consumption data.

Note that no information on group-specific demands is necessary.

The new model of aggregate consumer demand however does not come completely free. First, for the model to be theoretically valid, each group utility function is subject to an exact aggregation condition. Thus, not all well-behaved utility functions are admissible. On the other hand, the exact aggregation condition imposes only relatively mild restrictions on the pattern of consumption, especially if the number of commodities exceeds 3 , as we shall show by way of an example in the next section. Second, for the model to be empirically implemented, additional data on the joint distribution of income and attributes are, as indicated earlier, required. While these data can generally be obtained from income surveys, which are quite commonly available, they do constitute an additional requirement over and above what is necessary to implement a traditional model of aggregate consumer demand.

\section{EMPIRICAL IMPLEMENTATION}

In our empirical model of aggregate consumer demand, five broad categories of consumption expentitures are distinguished.

(1) Energy

(2) Agricultural products

(3) Consumer services

(4) Capital services

(5) Trade and transportation

Energy is the sum of all expenditures on energy items, such as electricity, gas, heating oil, gasoline, and the like. Agricultural products is the total of all. food expenditures (including beverages, tabacco, and alcohol), clothing expenditures, and other related expenditures. Consumer services refers to the sum of all service expenditures made by con- 
sumers, such as entertainment, maintenance and repairs, (automobile, plumbing, etc.), tailoring, cleaning, insurance, and the like. Capital services consists of a service flow from owned consumer durables, as well as a service flow from owned housing. Trade and transportation represents all expenditure margins paid by consumers to the retail and transportation sectors for delivery and presentation of other goods, as well as all expenditures paid directly for transportation services.

The demographic dimensions distinguished are

(1) Family size: 1, 2, 3, 4, 5, 6, and 7 or, more persons

(2) Age of head: $15-24,25-34,35-44,45-54,55-64,65$ and over

(3) Region of residence: Northeast, North Central, South, and West

(4) Race: White, Nonwhite

(5) Type of residence: Urban, Rural.

It is assumed that each household with vector of attributes equal to. $A$ has an indirect utility function of the translog form:

$$
\begin{aligned}
\operatorname{lnV}\left(\frac{P}{M}, A\right)=\alpha_{0} & +\Sigma_{i} \alpha_{i} \ln \left(\frac{P_{i}}{M}\right)+\Sigma_{i} \gamma_{1} A_{i} \\
& +\frac{1}{2} \Sigma_{i} \Sigma_{j} \beta_{i j} \ln \left(\frac{P_{i}}{M}\right) \ln \left(\frac{p_{j}}{M}\right)+\frac{1}{2} \Sigma_{i} \Sigma_{j} \delta_{i j} A_{i} A_{j} \\
& +\Sigma_{i} \Sigma_{j} \epsilon_{i j} \ln \left(\frac{p_{i}}{M}\right) A_{j},
\end{aligned}
$$

where withnut loss of generality, one may take $\left[\beta_{i j}\right]$ and $\left[\delta_{i j}\right]$ to be symmetric matrices. It is assumed, in addition, that the parameters of the translog function satisfy the exact aggregation condition. Thus:

$$
\begin{aligned}
& \Sigma_{i} \Sigma_{j} \beta_{i j}=0, \\
& \Sigma_{i} \epsilon_{i j}=0, \quad{ }_{j} .
\end{aligned}
$$

We note that these are relatively mild restrictions, especially if $\mathrm{m}$, the total number of commodity groups distinguished, is moderately large, say 4. We turther note the $\gamma_{1}^{\prime} \cdot$ and the $\delta_{i j}$ 's cannot be identified with any anount of individual or aggregate consumption data.

We note that the trauslog indirect utility function subject to these restrictions may be interpreted as a second-order approximation to any indirect utility function. which satisfies the exact aggregation condition. 
From this indirect utility function the consumption expenditure of the $n^{\text {th }}$ household on the $i^{\text {th }}$ commodity group is given by

$$
\begin{aligned}
\frac{p_{i} x_{n i}}{M_{n}} & =\frac{\alpha_{i}+\Sigma_{j} \beta_{i j} \ln \left(\frac{P_{j}}{M_{n}}\right)+\Sigma_{j} \delta_{i j} A_{j}}{-1+\Sigma_{i} \Sigma_{j} \beta_{i j} \ln p_{j}} \\
& =\frac{\alpha_{i}+\Sigma_{j} \beta_{1 j} \ln p_{j}-\left(\Sigma_{j} \beta_{i j}\right) \ln M_{n}+\Sigma_{j} \delta_{i j}{ }^{A} j}{-1+\Sigma_{i} \Sigma_{j} \beta_{i j} \ln p_{j}}
\end{aligned}
$$

The basic equation of aggregate consumption expenditure on the $i^{\text {th }}$ commodity group is then given by:

$$
\begin{aligned}
\sum_{n=1}^{N} p_{i} X_{n i}= & \frac{\alpha_{i}}{-1+\sum_{i} \Sigma_{j} \beta_{i j} \ln p_{j}}\left[\sum_{n=1}^{N} M_{n}\right] \\
& +\frac{1 \Sigma_{j} \beta_{i j} \ln p_{j}}{-1+\sum_{i} \Sigma_{j} \beta_{i j} \ln p_{j}}\left[\sum_{n=1}^{N} M_{n}\right] \\
& -\frac{\left(\Sigma_{j} \beta_{i j}\right) \sum_{n=1}^{N} M_{n} \ln M_{n}}{-1+\sum_{i} \Sigma_{j} \beta_{i j} \ln p_{j}} \\
& +\frac{\sum_{j} \delta_{i j}\left[\sum_{n=1}^{N} M_{n}\right] A_{n j}}{-1+\sum_{i} \Sigma_{j} \beta_{i j} \ln p_{j}}
\end{aligned}
$$

Note that $\left[\sum_{n=1}^{N} M_{n}\right],\left[\sum_{n=1}^{N} M_{n} \ell n M_{n}\right]$, and $\left[\sum_{n=1}^{N} M_{n} A_{n j}\right]$ 's can all be estinated from income surveys alone. In particular for the U.S. they can be estimated from the Current Population Surveys. The data requirements are thus quite parsimonious. Once estimates of the parameters for the aggregate consumption expenditure functions are obtained, these parameters of the different groups can be recovered by choosing appropriate values for the $A_{n j}$ 's.

Such a model of aggregate consumer demand, which takes into account not only prices and income but also the joint distribution of household incomes and attributes, has been formulated and implemented by Jorgenson, Lau, and Stoker ${ }^{2}$ for the United States. It can be estimated with aggregate time-series consumption data alone, or in conjunction with one or more cross-section data. (Indeed, cross-sections of subaggregate con- 
sumption data, such as state level data, can also be combined with aggregate time-series data.)

Once estimated, this model of aggregate consumer demand can be used to derive unique demand functions for each group of consumers distinguished by income and attributes. From the group-specific demand functions one can derive the group-specific utility functions. These empirically estinated group-specific utility functions. form the basis of the welfare comparison the results of which are presented in the next section.

\section{ANALYSIS OF COMPENSATING VARIATIONS}

Given the estimated demand (and hence utility) functions of the different groups, it is possible to calculate the net compensating variation required for each group to remain at the sane level of utility after the implementation of a new policy or project. The illustrative exercise that we have chosen to perform is an evaluation of the distributional impact of President Carter's domestic oil price decontrol program for the United States, based on our estimated system of aggregate consuner demand Eunctions.

The inputs needed for this exercise consist of price and inp Eorecasts for the years 1981-1985 for a inypothetical OPEC oil price scenario with and without: the inplementation of President Carter's domestic oil price decontrol program. It is assumed that there will be a $\$ 1.75$ surcharge on a barrel of DPE crude oil in 1979 , followed by a $2 \%$ p.a. real rate of increase over the $1980-1985$ period. The price and income forecasts over this period are generated by Edward Novicky of the Scientific Time Sharing Corporation using the Data Resources, Inc. Motel. These numbers are then translated into inputs compatible wilh uur aggregate consumer demand inotel.

The results of our. conpensating variations are presented in the foilowing tablcs. Table 1 describes the inputs, where the numbers 1 through 5 refer to the five commodity groups which are distinguished: energy, agricultural products, consumer services, capital services, and trade and transportation. Table 2 presents the income and expenditure projections. Table 3 presents the compensating variations, without regard to income 
changes, for households in different geographical and residential locations and of different ethnic groups, while Table 4 presents the net compensating variations. The reference levels of the other attributes are: 1979 income of $\$ 17,000$, household size of four, and age of head of household 35-44. Table 5 describes the changes in the expenditure patterns. Tables $6,7,8$ and 9 repeat Tables $2,3,4$ and 5 but for a reference level of 1979 income of $\$ 8,000$.

What do these tables show? On the whole, the rural households are much worse off than the urban households. White households are worse of $f$ than nonwhite households, but not by much. In terms of reglonal impact, the South is best of $f$, followed by the West, followed by the Northeast. The North Central requires the largest compensation. Low Income household $(\$ 8,000)$ are proportionately hurt much more than high income households $(\$ 17,000)$. The compensation required is always greater than one half although the household income is less than one half. It is perhaps a little surprising that the Northeast is not hurt as much as the North Central, it being the most vocal in terms of complaints. However, this finding is not unreasonable as residents in the Northeast use their automobiles much less and tend to live in higher densities than residents in the North Centra1. The West and South both have the benefit of a warm climate, although Westerners may have a slight edge in the intensity of the use of the automobile. There does not appear to be strong a priori reason why white households are hurt relatively more than nonwhte households, holding income constant. One possible explanation may lie in the differential residential patterns -- suburbs versus inner city, houses versus apartments -- which may account for the differences in the patterns of energy consumption. On the other hand, one should examine with some care the pattern of consumer-durable ownership, especially the types of automobiles and houses owned (or occupled).

Under the assumptions the net compensating variatlons are almost always negative, lending support to the President's program -- real income per capita is increased. The net compensating variation calculations are of courac subject to the caveat that the gross income gatns have been distributed proportiona1ly across the base level income. To the extent, as is likely, that the income gains due to decontrol are not distributed 
proportionally across all households, the net compensating variations calculation may change drastically. What is needed is a detailed identification of the sources of income by groups and a determination of whether the different sources are likely to be increased proportionally. It is, for example, obvious that groups largely dependent on fixed incomes will be unable to share in the income gains proportionally, at least not without a time lag.

The consumption sector which shows the most gain is nondurable consumer services (other than trade and transportation).

Finally, we should note that the inpurs used are taken from the DRI model as run by Edward Noviciky. They are not completely consistent since the demands predicted by our model are not fed back into the DRI model. It is thus not a fully general equilibrium exercise.

\section{APPLICATION FOR LONG-TERM PROJECTION}

The computation of group-specific welfare impacts is not the only application of such a model of aygregate consumer demand. Since unique group-specific denand functions can be derivel from this nodel, it may be used to project group-specific consumption patterns in response to changes in prices, incomes, quantity constraints, and ullei govornnent policies. This can be readily accomplished in this model without costly and time-consuming simulations at the microecomonic lovel.

In addition, if interest is primarliy [ucusted on the quantity nf aggregate consumption, as in many applications, such a model of aggregate consumption offars a unique advantage. It can be used to generate, almosi instantanemusly, a projection of aggregate consumption, given the prices, incomes, and information on the joint distribution of household incoines and attributes. No microeconomic level simulation is required. Moreover, the mortel can assiulilate dircctly information of the changing demograpinic and income dfscribulions whtch may inteed be highly relevant in medium to long-term projections.

\section{EXTENSIONS}

The methodology described in this paper can be extended in nany directions. First, it can be adapted to accommodate prices which may vary 
across different groups of households because of transportation costs, progressivity of the income tax, and other factors. Thus, for example, any policy or project which has a differential impact on the prices of different regions can be evaluated with this methodology with respect to the distribution of the welfare gains and losses. Second, the methodo1ogy can be adapted to take. into account the varying "basic needs" across groups of households. This can be done, for example, through the introduction of price-dependent indices of incomes and attributes in the aggregate demand function. Third, the methodology can be extended to include an analysis of household purchase and ownership of durable consumer goods, and the effect of such ownership on the consumption pattern. This can be done, for example, by treating the quantity and type of consumer durables owned as another dimension of the vector of attributes. Finally, it is necessary to extend this methodology to include dynamic elements of consumer behavior. 
Table 1

SOENARIO 175-2

PRICE PROJECTIONS (NORMALIZED TO 1 IN 1972)

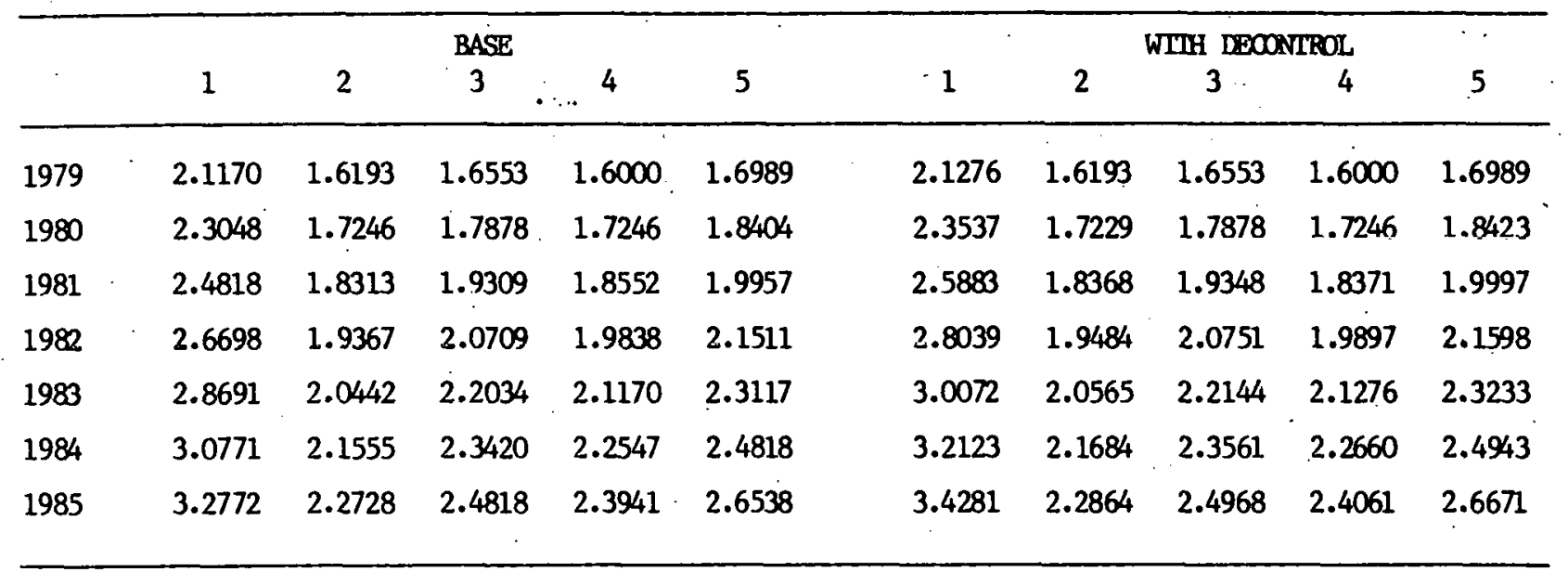

Table 2

SCENARIO 175-2 1979 INCOME \$17,000

INCONE AND EXPENDITURE PRAJECLIONS

\begin{tabular}{|c|c|c|c|c|c|c|}
\hline & \multicolumn{2}{|c|}{ BABE } & \multicolumn{2}{|c|}{ WLIH DECONTROL } & \multicolumn{2}{|c|}{ CHANGES } \\
\hline & $I$ & M & $I$ & M & I & $\mathbf{M}$ \\
\hline 1979 & 17000.00 & 15740.98 & 17000.00 & 15740.98 & .00 & .00 \\
\hline 1980 & 18720.93 & 17334.46 & 18758.20 & 17368.97 & 37.27 & 34.51 \\
\hline 1981 & $20651: 22$ & 19121.79 & 20766.33 & 19238.38 & 115.11 & 106.58 \\
\hline 1982 & 22354.96 & 20699.35 & 22527.57 & 20859.18 & 172.61 & 159.83 \\
\hline 1983 & 24520.38 & 22704.40 & 24705.32 & 22875.64 & 184.94 & 171.24 \\
\hline 1984 & 26970.78 & 24973.32 & 27180.49 & 25167.50 & 209.71 & 194.18 \\
\hline 1985 & 29450.61 & 27269.50 & 29710.52 & 27510.16 & 259.91 & 240.66 \\
\hline
\end{tabular}


Table 3

SCENARIO 175-2 1979 INCOME $\$ 17,000$

COMPENSATING VARIATTONS

\begin{tabular}{|c|c|c|c|c|c|c|c|c|c|}
\hline \multirow[b]{3}{*}{ YEAR } & \multicolumn{4}{|c|}{ NORTHEAST } & & \multicolumn{4}{|c|}{ NARIH CENIRAL } \\
\hline & \multicolumn{2}{|c|}{ LRBAN } & \multicolumn{2}{|c|}{ RURAL } & & \multicolumn{2}{|c|}{ URBAN } & \multicolumn{2}{|c|}{ RURAL } \\
\hline & WHITE & - NONWHLIE & WHITE & NONWHTE & & WHCIE & NONWHITE & WHIIE & NONWHITE \\
\hline 1979 & 4.14 & 3.80 & 5.45 & 5.11 & & 4.83 & 4.48 & 6.13 & 5.79 \\
\hline 1980 & 21.60 & 20.05 & 26.93 & 25.38 & & 24.41 & 22.86 & 29.75 & 28.20 \\
\hline 1981 & 81.38 & 78.51 & 92.92 & 90.06 & & 88.16 & 85.29 & 99.71 & 96.84 \\
\hline 1982 & 127.61 & 124.47 & 140.68 & 137.53 & & 136.19 & 133.04 & 149.26 & 146.11 \\
\hline 1983 & 175.41 & 171.39 & 191.10 & 187.08 & & 183.89 & 179.87 & 199.58 & 195.56 \\
\hline 1984 & 193.84 & 189.94 & 209.37 & 205.46 & & 202.20 & 198.30 & 217.73 & 213.82 \\
\hline \multirow[t]{3}{*}{1985} & 215.86 & 211.36 & 233.73 & 229.23 & & 225.47 & 220.96 & 243.34 & 238.84 \\
\hline & \multicolumn{4}{|c|}{ SOUIH } & & \multicolumn{4}{|c|}{ WEST } \\
\hline & \multicolumn{2}{|c|}{ URBAN } & \multicolumn{2}{|c|}{ RURAL } & & \multicolumn{2}{|c|}{ URBAN } & \multicolumn{2}{|c|}{ RURAL } \\
\hline YEAR & WHLTE & NONWHELE & WHITE & NONWHITE & & WHITE & NONWHTIE & WHTE & NONWHLTE \\
\hline 1979 & 2.79 & 2.45 & 4.10 & 3.75 & : & 3.41 & 3.06 & 4.71 & 4.37 \\
\hline 1980 & 16.26 & 14.71 & 21.59 & 20.04 & & 18.50 & 16.95 & 23.83 & 22.28 \\
\hline 1981 & 67.97 & 65.11 & 79.51 & 76.64 & & 74.20 & 71.34 & 85.75 & 82.88 \\
\hline 1982 & 111.56 & 108.42 & 124.62 & 121.47 & & 119.23 & 116.09 & 132.29 & 129.14 \\
\hline 1983 & 158.64 & 154.62 & 174.31 & 170.30 & & 166.43 & 162.41 & 182.11 & 178.09 \\
\hline 1984 & 176.80 & 172.90 & 192.31 & 188.41 & & 184.68 & 180.78 & 200.20 & 196.30 \\
\hline 1985 & 196.30 & 191.80 & 214.16 & 209.66 & & 205.34 & 200.84 & 223.20 & 218.70 \\
\hline
\end{tabular}


Table 4

SCENARIO 175-2 1979 INOOME $\$ 17,000$

MINUS NET COMPENSATING VARIATIONS

\begin{tabular}{|c|c|c|c|c|c|c|c|c|c|}
\hline \multirow[b]{3}{*}{ YEAR } & \multicolumn{4}{|c|}{ NORIHEAST } & \multicolumn{5}{|c|}{ NORIH CENIRAL } \\
\hline & \multicolumn{2}{|c|}{ URBAN } & \multicolumn{2}{|c|}{ RURAL - } & \multicolumn{2}{|c|}{ URBAN } & & \multicolumn{2}{|c|}{ RURAL } \\
\hline & WHIIE & NONWHITE & WHIIE & NONWHITE & WHTIE & NONWHIE & & WHETE & NONWHITE \\
\hline 1979 & -4.14 & -3.80 & -5.45 & -5.11 & -4.83 & -4.48 & & -6.13 & -5.79 \\
\hline 1980 & 15.67 & 17.22 & 10.34 & 11.89 & 12.86 & 14.41 & & 7.52 & 9.07 \\
\hline 1981 & 33.73 & $36.6 n$ & 22.19 & 25.05 & 26.93 & 29.82 & & 15.40 & 18.27 \\
\hline 1982 & 45.00 & 48.14 & 31.93 & 35.08 & 36.42 & 39.57 & & 23.35 & 26.50 \\
\hline 1983 & 9.53 & 13.55 & -6.16 & -2.14 & 1.05 & 5.07 & & -14.64 & -10.62 \\
\hline 1984 & 15.87 & 19.77 & .34 & 4.25 & 7.51 & 11.41 & & -8.02 & -4.11 \\
\hline \multirow[t]{3}{*}{1985} & 44.05 & 48.55 & 26.18 & 30.68 & 34.44 & 38.95 & & .16 .57 & 21.07 \\
\hline & \multirow{2}{*}{\multicolumn{2}{|c|}{ URBAN }} & & & & & ST & & \\
\hline & & & \multicolumn{2}{|c|}{ RURAL } & \multicolumn{2}{|c|}{ URBAN } & & \multicolumn{2}{|c|}{ RURAL } \\
\hline YFAR & WHITE & NONWHLTE & WHГTE & NONWHTTE & WH'IE & NONWHTIE & & WHIIE & NONWHCTE \\
\hline 1979 & -2.79 & -2.45 & -4.10 & -3.75 & -3.41 & -3.06 & & -4.71 & -4.37 \\
\hline 1980 & 21.01 & 22.56 & 15.68 & 17.23 & 18.77 & 20.32 & & 13.44 & 14.99 \\
\hline 1981 & 47.14 & 50.00 & 35.60 & 38.47 & 40.91 & 43.77 & & 29.36 & 32.23 \\
\hline 1982 & 61.05 & 64.19 & 47.99 & 51.14 & 53.30 & 56.52 & & 40.32 & 43.47 \\
\hline 1983 & 26.30 & 30.32 & 10.63 & 14.64 & 18.51 & 22.53 & & 2.83 & 6.85 \\
\hline 1984 & 32.91 & 36.81 & 17.40 & 21.30 & 25.03 & 28.93 & & 9.51 & 1.3 .41 \\
\hline 1985 & 63.61 & 68.11 & 45.75 & 50.25 & 54.57 & 59.07 & & 36.71 & 41.21 \\
\hline
\end{tabular}


Table 5

SCENARIO 175-2 1979 INOOME $\$ 17,000$

TYPICAL EXPENDITURE PATIERNS

\begin{tabular}{lccccccccccc}
\hline & & \multicolumn{3}{c}{ BASE } & \multicolumn{3}{c}{ WTTH DECONTROL } \\
& 1 & 2 & 3 & 4 & 5 & 1 & 2 & 3 & 4 & 5 \\
\hline 1979 & 828.65 & 3318.60 & 3548.40 & 3238.52 & 4806.81 & 829.15 & 3308.81 & 3551.79 & 3238.43 & 4812.79 \\
1980 & 940.98 & 3585.17 & 3924.40 & 3571.86 & 5312.05 & 948.07 & 3542.92 & 3949.54 & 3576.2 & 5352.17 \\
$1981 .$. & 1075.66 & 3890.67 & 4342.96 & 3934.67 & 5877.83 & 1082.65 & 3811.39 & 4396.65 & 3966.21 & 5971.48 \\
1982 & 1204.99 & 4155.47 & 4726.97 & 4219.12 & 6392.80 & 1211.20 & 4066.52 & 4799.61 & 4263.76 & 6518.09 \\
1983 & 1351.41 & 4472.32 & 5205.57 & 4644.94 & 7030.16 & 1363.72 & 4385.28 & 5282.73 & 4690.30 & 7153.61 \\
1984 & 1517.22 & 4821.81 & 5744.56 & 5142.81 & 7746.83 & 1531.72 & 4737.05 & 5825.58 & 5194.24 & 7878.91 \\
1985 & 1679.45 & 5188.39 & 6284.10 & 5652.09 & 8465.46 & 1697.03 & 5091.87 & 6380.77 & 5718.86 & 8621.64 \\
\hline
\end{tabular}

\section{Table 6}

SCENARTO 175-2 1979 INCONE $\$ 8,000$

INOONE AND EXPENDITURE PROJECTIONS

\begin{tabular}{|c|c|c|c|c|c|c|c|}
\hline & \multicolumn{2}{|c|}{ BASE } & \multicolumn{2}{|c|}{ WTIH DECONIROL } & & \multicolumn{2}{|c|}{ CHANGES } \\
\hline & I & M & I & M & & I & M \\
\hline 1979 & 8000.00 & 7407.52 & 8000.00 & 7407.52 & & .00 & .00 \\
\hline 1980 & 8809.85 & 8157.39 & 8827.39 & 8173.63 & & 17.54 & 16.24 \\
\hline 1981 & 9718.22 & 8998.49 & $9772: 39$ & 9m4R.65 & . & 54.17 & 50.16 \\
\hline 1982 & 10519.98 & 9740.87 & 10601.21 & 9816.08 & & 81.23 & 75.21 \\
\hline 1983 & 11539.00 & 10684.42 & 11626.03 & 10765.01 & & 87.03 & 80.59 \\
\hline 1984 & 12692.13 & 11752.15 & 12790.82 & 11843.53 & & 98.69 & 91.38 \\
\hline 1985 & 13859.11 & 12832.70 & 13981.42 & 12945.96 & & 122.31 & 113.25 \\
\hline
\end{tabular}


Table 7

SCENARIO 175-2 1979 INCOME \$8000

COMPENSATING VARIATIONS

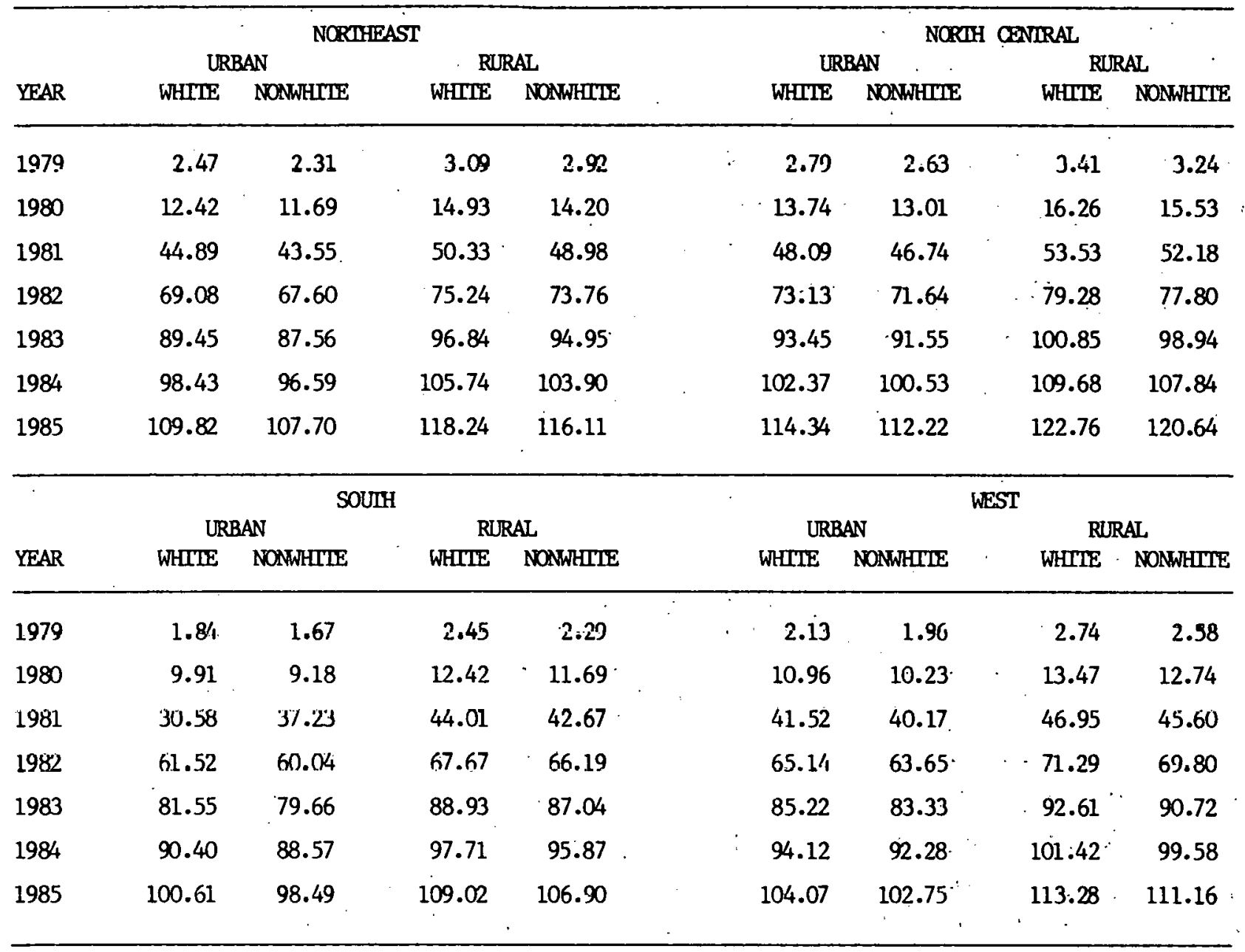


Table 8

SCENARIO 175-2 1979 INCOME \$8000

MINUS NET COMPENSATING VARIATIONS

\begin{tabular}{|c|c|c|c|c|c|c|c|c|}
\hline \multirow[b]{3}{*}{ YEAR } & \multicolumn{4}{|c|}{ NORIHEAST } & \multicolumn{4}{|c|}{ NORTH CENIRAL } \\
\hline & \multicolumn{2}{|c|}{ URBAN } & \multicolumn{2}{|c|}{ RURAL } & \multicolumn{2}{|c|}{ URBAN } & \multicolumn{2}{|c|}{ RURAL } \\
\hline & WHIIE & NONWHEIEE & WHITE & NONWHLLE & WHITE & NONWHITE & WHITE & NONWHTTE \\
\hline 1979 & -2.47 & -2.31 & -3.09 & -2.92 & -2.79 & -2.63 & -3.41 & -3.24 \\
\hline 1980 & 5.12 & 5.85 & 2.61 & 3.34 & 3.79 & 4.52 & 1.28 & 2.01 \\
\hline 1981 & 9.27 & 10.62 & 3.84 & 5.18 & 6.08 & 7.43 & .64 & 1.99 \\
\hline 1982 & 12.14 & 13.63 & 5.99 & 7.47 & 8.10 & 9.59 & 1.95 & 3.43 \\
\hline 1983 & -2.42 & -.53 & -9.81 & -7.92 & -6.41 & -4.52 & -13.80 & -11.91 \\
\hline 1984 & .26 & 2.09 & -7.05 & -5.21 & -3.68 & -1.84 & -10.99 & -9.15 \\
\hline 1985 & 12.49 & 14.61 & 4.07 & 6.20 & 7.97 & 10.09 & -.45 & 1.67 \\
\hline \multicolumn{5}{|c|}{ SOUIH } & \multicolumn{4}{|c|}{ WEST } \\
\hline & \multicolumn{2}{|c|}{ URBAN } & \multicolumn{2}{|c|}{ RURAL } & \multicolumn{2}{|c|}{ URBAN } & \multicolumn{2}{|c|}{ RURAL } \\
\hline YEAR & INHTIE & NONWHLIE & WHITE & NOWWHITE & WHITE & NOAWHIIE & WHITE & NONWHITE \\
\hline 1979 & -1.84 & -1.67 & -2.45 & -2.29 & -2.13 & -1.96 & -2.74 & -2.58 \\
\hline 1980 & 7.63 & 8.36 & 5.12 & 5.85 & 6.58 & 7.31 & 4.07 & 4.80 \\
\hline 1981 & 15.59 & 16.94 & 10.15 & 11.50 & 12.65 & 14.00 & 7.22 & 8.56 \\
\hline 1982 & 19.70 & 21.18 & 13.55 & 15.04 & 16.09 & 17.57 & 9.94 & 11.42 \\
\hline 1983 & 5.48 & 7.37 & -1.90 & -.01 & 1.81 & 3.70 & -5.58 & -3.68 \\
\hline 1984 & 8.28 & $10.12^{\circ}$ & .98 & 2.82 & 4.57 & 6.41 & -2.74 & -.90 \\
\hline 1985 & 21.70 & 23.82 & 13.29 & 15.41 & 17.44 & 19.56 & 9.03 & 11.15 \\
\hline
\end{tabular}


Table 9

SCENARIO 175-2 1979 INOOME $\$ 8000$

TYPICAL EXPENDITURE PATTERNS

\begin{tabular}{|c|c|c|c|c|c|c|c|c|c|c|}
\hline & \multirow[b]{2}{*}{1} & \multicolumn{4}{|c|}{ BASE } & \multicolumn{5}{|c|}{ WITH DECONIROL } \\
\hline & & 2 & 3 & 4 & 5 & 1 & 2 & 3 & 4 & 5 \\
\hline 1979 & 494.20 & 1930.31 & 1843.55 & 652.94 & 2486.51 & 494.43 & 1925.67 & 1845.13 & 652.98 & 2489.31 \\
\hline 1980 & 557.66 & 2093.21 & 2038.14 & 721.30 & 2747.08 & 561.18 & 2073.98 & 2050.28 & 721.82 & 2766.37 \\
\hline 1981 & 632.93 & 2279.02 & 2254.93 & 792.68 & 3038.94 & 636.80 & 2243.77 & 2281.17 & 802.65 & 3084.26 \\
\hline 1982 & 704.29 & 2440.77 & 2453.14 & 838.77 & 3303.90 & 708.11 & 2402.06 & 2488.81 & 852.33 & 3364.77 \\
\hline 1983 & 786.53 & 2637.01 & 2700.58 & .927 .76 & 3632.54 & 793.33 & 2599.62 & 2738.57 & 940.69 & 3692.80 \\
\hline 1984 & 879.65 & 2854.84 & 2979.37 & 1035.95 & 4002.34 & 887.63 & 2819.03 & 3019.42 & 1050.51 & 4066.93 \\
\hline 1985 & 971.26 & 3081.33 & 3258.71 & 1148.06 & 4373.35 & 980.97 & 3041.01 & 3306.61 & 1167.42 & 4449.95 \\
\hline
\end{tabular}

\section{REFERENCES}

1. W.M. Gorman, "Community Preference Fields," Econometrica, 21, 1953, 63-80.

2. D.W. Jorgenson, L.J. Lau and, T.M. Stoker, A Transcendental Logarithmic Model of Aggregate Consumer Behavior,: Department of Economics, Harvard University, 1979.

3. L.J. Lau, Existence Conditions for Aggregate Demand Functions: The Case of a Single Index, Technical Report No. 248, Institute for Mathematical Studies in the Social Sciences, Stanford University, 1977.

4. L.J. Lau, Existence Conditions for Aggregate Demand Function: The Case of Multiple Indexes, Technical Report No. 249, Institute for Mathematical Studies in the Social. Sciences, Stanford University, 1977. 